\title{
Medical cannabis use in the Australian community following introduction of legal access: The 2018- 2019 Online Cross-Sectional Cannabis as Medicine Survey (CAMS-18)
}

Nicholas Lintzeris ( $\nabla$ nicholas.lintzeris@health.nsw.gov.au )

South Eastern Sydney Local Health District https://orcid.org/0000-0001-5229-8257

Llewellyn Mills

The University of Sydney School of Medicine

Anastasia Suraev

The University of Sydney, Lambert Initiative of Cannabinoid Therapeutics

Maria Bravo

The University of Sydney School of Medicine

Thomas Arkell

University of Sydney Lambert Intiative Cannabniod Therapeutics

Jonathon C Arnold

University of Sydney Lambert Intiative Cannabinoid Therapeutics

Melissa J Benson

University Sydney Lambert Initiative Cannabinoid Therapeutics

lain S McGregor

University Sydney Lambert Initiative Cannabinoid Therapeutics

Research

Keywords: medical cannabis, medical marijuana, epidemiology, health policy

Posted Date: February 21st, 2020

DOI: https://doi.org/10.21203/rs.2.24266/v1

License: (c) (i) This work is licensed under a Creative Commons Attribution 4.0 International License.

Read Full License

Version of Record: A version of this preprint was published at Harm Reduction Journal on June 8th, 2020.

See the published version at https://doi.org/10.1186/s12954-020-00377-0. 


\section{Abstract}

Background : In 2016 the Australian federal government passed legislation enabling a range of cannabisbased products to be prescribed to patients by registered healthcare professionals. An online survey conducted immediately prior to these legislative changes found that the vast majority of respondents at the time were illicitly sourcing cannabis plant matter, smoking was the preferred route of administration, and mental health, chronic pain, and sleep conditions were the most frequently cited reasons for medical cannabis use. This manuscript reports the results of a follow-up survey conducted in 2018-2019, the Cannabis As Medicine Survey (CAMS-18). The goal of this second questionnaire was to examine patterns of use and consumer perspectives regarding medical cannabis use in Australia, two years after the introduction of legal access pathways.

Methods : Anonymous online cross-sectional survey with convenience sample, recruited mainly through online media between September 2018 and March 2019. Participants were adults (18 years or over) residing in Australia who reported using a cannabis product for self-identified therapeutic reasons during the preceding 12 months. The survey measured consumer characteristics; indications and patterns of medical cannabis use; routes and frequency of administration; perceived benefits and harms; experiences and preferred models of access to medical cannabis.

Results : Data were available for 1388 respondents. The main categories of condition being treated with medical cannabis were pain (36.4\%), mental health (32.8\%), sleep (9.2\%), neurological (5.2\%) and cancer (3.8\%). Respondents reported using medical cannabis on 15.8 (11.2) days in the past 28, by inhaled $(71.4 \%)$ or oral $(26.5 \%)$ routes and spending AUD\$82.27 (\$101.27) per week. There were high levels of self-reported effectiveness, but also high rates of side effects. There was uncertainty regarding the composition of illicit cannabinoid products and concerns regarding their possible contamination. Few respondents $(2.7 \%)$ had accessed legally prescribed medical cannabis, with the main perceived barriers being cost, dis-interest from the medical profession, and stigma regarding cannabis use.

Conclusions : Chronic pain, mental health and sleep remain the main clinical conditions for which consumers report using medical cannabis. Despite two years of legal availability, most consumers in Australia reported accessing illicit cannabis products, with uncertainty regarding the quality or composition of cannabis products.

\section{Introduction}

The global trend towards the legalisation of cannabis for medical purposes reflects both the increased robustness of evidence supporting efficacy ${ }^{1}$ and increased interest amongst consumers in using cannabis-based therapeutics ${ }^{2}$. In this rapidly changing landscape, it is important for regulators and healthcare providers to understand community use of cannabis for medical purposes, and to determine how changes in medical cannabis legislation may impact patterns of use. 
In November 2016, the Australian federal government passed legislation ${ }^{3,4}$ enabling a range of cannabisbased products to be prescribed as unregistered medicines using the Special Access Scheme (SAS) and Authorised Prescriber Schemes ${ }^{5,6}$, and in December 2016 the Australian Therapeutic Goods Administration (TGA) published clinical guidance ${ }^{5}$ regarding their use for a range of conditions. At the time of writing, more than 25,000 official approvals have been issued to patients to allow access to more than 50 different cannabis-based products including botanical material, oils and sprays ${ }^{6,7}$. Approvals cover a wide range of conditions but by far the largest category is chronic pain ${ }^{8,9}$.

Immediately prior to the legislative changes allowing access, our research group conducted an online consumer survey ('Cannabis as Medicine Survey 2016' or CAMS-16) of Australians who had indicated use of a cannabis-based product (either legally or illegally) for the management of a health condition in the preceding 12 months $^{10}$. The vast majority of respondents at the time were illicitly sourcing cannabis plant matter, with smoking being the preferred route of administration. Mental health, chronic pain, and sleep conditions were the most frequently cited reasons for medical cannabis use. Respondents generally reported high levels of effectiveness, but also reported significant levels of, mostly minor, side effects.

Here we report the results of a follow-up survey conducted approximately two years after the introduction of these legislative changes. The CAMS-18 survey, which recruited during the last quarter of 2018 and first quarter of 2019, involved many of the same questions as CAMS-16 to enable general comparisons to be made of consumer experiences over time, but also included refinement of various sections including extra questions regarding composition of cannabis products and perceptions of legal prescription cannabis models of care.

As with the CAMS-16 survey, the term 'medical cannabis' used in this paper refers to the term understood by lay people - any licit or illicit cannabis-based product (including plant matter) used to treat or alleviate the symptoms of a self-identified health condition. This does not imply that the cannabis product was indicated or prescribed by a health professional.

\section{Methods}

The study used a cross-sectional online survey design with a convenience sample of individuals selfreporting the use of cannabis for therapeutic reasons within the past 12 months. The study was approved by the University of Sydney Human Research Ethics Committee (2018/544). Survey questions examined the following areas:

\section{a)}

medical conditions for which respondents reported using medical cannabis;

b)

current and lifetime patterns of medical and non-medical cannabis use, including source, route of administration, average frequency and cost.

c) 
perceived benefits and harms associated with medical cannabis use, including side effects (symptom checklist); social and legal implications; and Patient Global Impression of Change (PGIC) ${ }^{11}$, a 7-item patient-reported rating of symptom change.

d)

the cannabinoid profile that respondents thought they were using (options of tetrahydrocannabinol (THC), cannabidiol (CBD), and THC:CBD combinations).

e)

perspectives on accessing licit medical cannabis products - including the experiences of those who had accessed legally prescribed products, and reasons for not accessing prescribed products for respondents using only illicit products.

Study data were collected and managed using Research Electronic Data Capture (REDCap), a secure webbased platform allowing respondents to directly enter responses online ${ }^{12}$.

The CAMS-18 survey was freely accessible to any person who was supplied with the survey URL. The survey was 'live' online for six months (September 2018 to March 2019), and was promoted online using social media and consumer group webpages, and at consumer and professional forums. Eligibility criteria were: (a) informed consent, (b) aged $\geq 18$ years, (c) self-identified as a user of cannabis or a cannabinoid product for a medical purpose within the previous 12 months, and (d) resident in Australia.

\section{Statistical Analyses}

Descriptive statistics were performed in $\mathrm{R}$ version $3.4 .1^{13}$ using the tidyverse $\mathrm{e}^{14}$ package. Only valid responses are reported, with no imputation for missing data. As the number of valid responses varied across different items in the survey, categorical variable frequencies are reported alongside the number of valid responses.

\section{Patient and Public Involvement}

The CAMS-16 survey was extensively piloted with medical cannabis users through cooperation with cannabis user organisations across Australia. CAMS-16 item selection and survey design was thus heavily informed by patient and public feedback. CAMS-18 was based on CAMS-16, with minor changes, and was piloted with a group of consumers reporting medical cannabis use for user-acceptance and ease of understanding of the questionnaire.

\section{Results}

Respondents

Of the 1804 respondents who commenced the survey, 184 did not meet eligibility criteria, and 192 did not give consent. Data were excluded for 70 respondents who provided no further information beyond demographics questions, 3 respondents who indicated that none of their cannabis use was for medical 
purposes, and 7 who provided implausible responses to numerous questions. Of the remaining 1388 respondents, 909 (65\%) completed the entire survey.

Most respondents became aware of the survey via social media: 336/1387 (24.2\%) through Facebook, and $827 / 1387$ (59.5\%) through "Other social media (e.g. Instagram, Twitter, Snapchat)". Others were recruited through friends $(4.7 \%, 65 / 1387)$, medical cannabis providers $(2.2 \%, 31 / 1387)$, the Lambert Initiative website $(1.7 \%, 23 / 1387)$, doctors/healthcare providers $(1.0 \%, 14 / 1387)$, consumer groups $(0.9 \%$, $13 / 1387)$, traditional media (TV, radio, newspaper) $(0.8 \%, 11 / 1387)$, and 'other' sources $(4.5 \%, 62 / 1387)$.

\section{Participant Characteristics}

The majority of respondents (Table 1$)$ were male $(57.6 \%, 799 / 1387)$, with a mean age of $43.4 \pm$ 13.9 years. Most respondents were employed $(59.2 \%, 821 / 1387)$ and had attained either a trade/vocational certificate or a university degree $(78.7 \%, 1092 / 1387)$.

Table 1

Demographic Characteristics of the CAMS-18 Sample $(n=1387)$

\section{Characteristic}

Age, mean (SD)

$43.4(13.9)$

Gender

$560(40.4 \%)$

Female $799(57.6 \%)$

Male

Other

Relationship Status

Partnered (currently in relationship, including defacto and married)

Single (not currently in a relationship, including separated, divorced, widowed)

Indigenous Status

Aboriginal and/or Torres Strait Islander

Not Aboriginal and/or Torres Strait Islander

Highest Education Level Attained

Primary School

Secondary School

Trade or Vocational College

University Degree

Other

$861(62.1 \%)$

$526(37.9 \%)$

Employment Status

Full-time work

Part-time work

Home duties

Student

Unemployed

Retired

Note: Missing values excluded from denominator when calculating percentages. 
Cannabis Use

Lifetime cannabis use history indicated that 19.1\% (212/1109) had never used cannabis prior to using it for medical reasons, 35.7\% (396/1109) reported previous non-medical cannabis use but had quit for 12 months or more prior to initiating medical cannabis use, and 45.2\% (501/1109) were using cannabis nonmedically at the time they began using it medically.

\section{INSERT Table 1}

The mean estimated proportion of cannabis use for medical purposes (as a proportion of total use) was $83.2 \pm 20.6 \%$ (Table 2). Respondents reported using medical cannabis on a median of 18 days in the past 28 days $(\mathrm{IQR}=4,28 ;$ mean $=15.8 \pm 11.2)$.

Table 2

Patterns of Cannabis Use

\section{Characteristic}

Age first tried cannabis for any reason, Mean (SD)

Age first regular cannabis use any reason, Mean (SD)

Age first regular cannabis use for medical reason, Mean (SD)

Never used cannabis regularly for any reason, $\mathrm{N}(\%)$

Number of days in previous 28 used cannabis for any reason

Mean (SD)

Median (IQR)

Number of days in previous 28 used cannabis for medical reasons

Mean (SD)

Median (IQR)

Estimated proportion of cannabis use for medical reasons, mean (SD)

Usual number of times using cannabis per day for any reason

Mean (SD)

Median (IQR)

Weekly cost of medical cannabis, Mean (SD)

Weekly cost of medical cannabis with respondents who did not pay excluded, Mean (SD)

\section{n}

$1110 \quad 20.5(11.6)$

$1110 \quad 25.8(16.3)$

$111032.6(17.5)$

$1110134(12.1 \%)$

$1110 \quad 17.3(10.9)$

$20(5-28)$

1110

$15.8(11.2)$

$18(4-28)$

$109583.2 \%$

$(20.6 \%)$

$1110 \quad 3.3(3.7)$

$2(1-4)$

$1101 \$ 60.68$

$(\$ 94.20)$

$812 \$ 82.30$

(\$101.00)

Median (IQR) reported for count variables only. IQR = Interquartile range

\section{INSERT Table 2}


Most respondents consumed their cannabis via an inhaled $(71.4 \% ; 788 / 1104)$ or oral $(26.5 \%, 293 / 1104)$ route, although there was a much stronger preference for oral or vaporised routes of administration than smoked routes (Fig. 1).

\section{INSERT Fig. 1}

\section{Composition of Medical Cannabis}

Respondents reported they either did not know the composition of their cannabis $(25.8 \%, 284 / 1103)$ or that it varied significantly between batches $(23.9 \%, 264 / 1103) .16 .4 \%(181 / 1103)$ reported their medical cannabis contained approximately equal levels of THC and CBD, $21.3 \%(235 / 1103)$ reported it contained predominately THC (with either no, or small amounts of other cannabinoids), $12.2 \%$ (135/1103) reported it contained predominately CBD, and $0.4 \%(4 / 1103)$ reported 'other'. Most $(63.4 \%, 699 / 1105)$ were concerned about the possibility of contaminants (e.g. heavy metals, pesticides) in their cannabis.

\section{Conditions Treated with Medical Cannabis}

Respondents were asked to select from a structured list, up to five health conditions ("All reasons", Table 3), and the main condition (see "Main reason") for their medical cannabis use. The categories most commonly endorsed for "All reasons" were pain $(61.6 \%, 852 / 1388)$, sleep $(49.1 \%, 679 / 1388)$ and mental health/substance use conditions (44.9\%, 621/1388; see Table 3$)$. The most frequent "Main reasons" were anxiety $(12.6 \%, 168 / 1331)$, back pain $(10.1 \%, 135 / 1331)$, depression $(8.5 \%, 113 / 1331)$ and insomnia $(7.1 \%, 94 / 1331)$. 
Table 3

Conditions reported as reasons for using medical cannabis ${ }^{a}$.

\begin{tabular}{|c|c|c|}
\hline Condition & $\begin{array}{l}\text { Main reason }{ }^{b} \\
(n=1331)\end{array}$ & $\begin{array}{l}\text { All reasons } \\
(n=1382)\end{array}$ \\
\hline $\begin{array}{l}\text { PainTotal } \\
\text { Back } \\
\text { Arthritis } \\
\text { Neuropathy } \\
\text { Other } \\
\text { Fibromyalgia }\end{array}$ & $\begin{array}{l}485(36.4 \%) \\
135(10.1 \%) \\
79(5.9 \%) \\
75(5.6 \%) \\
53(4.0 \%) \\
52(3.9 \%)\end{array}$ & $\begin{array}{l}852(61.6 \%) \\
477(34.5 \%) \\
262(19.0 \%) \\
194(14.0 \%) \\
123(8.9 \%) \\
122(8.8 \%)\end{array}$ \\
\hline $\begin{array}{l}\text { Mental HealthTotal } \\
\text { Anxiety } \\
\text { Depression } \\
\text { PTSD } \\
\text { Addiction to other substances } \\
\text { ADHD }\end{array}$ & $\begin{array}{l}437(32.8 \%) \\
168(12.6 \%) \\
113(8.5 \%) \\
82(6.2 \%) \\
13(1.0 \%) \\
13(1.0 \%)\end{array}$ & $\begin{array}{l}621(44.9 \%) \\
450(32.6 \%) \\
386(27.9 \%) \\
191(13.8 \%) \\
67(4.8 \%) \\
61(4.4 \%)\end{array}$ \\
\hline $\begin{array}{l}\text { SleepTotal } \\
\text { Insomnia } \\
\text { Circadian rhythm disorder } \\
\text { Sleep movement disorder } \\
\text { Sleep breathing disorder } \\
\text { Other }\end{array}$ & $\begin{array}{l}123(9.2 \%) \\
94(7.1 \%) \\
9(0.7 \%) \\
9(0.7 \%) \\
8(0.6 \%) \\
2(0.2 \%)\end{array}$ & $\begin{array}{l}679(49.1 \%) \\
573(41.5 \%) \\
74(5.4 \%) \\
140(10.1 \%) \\
55(4.0 \%) \\
8(0.6 \%)\end{array}$ \\
\hline $\begin{array}{l}\text { CancerTotal } \\
\text { Blood } \\
\text { Other } \\
\text { Gastrointestinal } \\
\text { Brain } \\
\text { Breast }\end{array}$ & $\begin{array}{l}50(3.8 \%) \\
8(0.6 \%) \\
8(0.6 \%) \\
6(0.5 \%) \\
5(0.4 \%) \\
5(0.4 \%)\end{array}$ & $\begin{array}{l}106(7.7 \%) \\
14(1.0 \%) \\
18(1.3 \%) \\
14(1.0 \%) \\
15(1.1 \%) \\
19(1.4 \%)\end{array}$ \\
\hline $\begin{array}{l}\text { NeurologicalTotal } \\
\text { Epilepsy } \\
\text { Autism } \\
\text { Other } \\
\text { Multiple sclerosis } \\
\text { Dementia }\end{array}$ & $\begin{array}{l}69(5.2 \%) \\
26(2.0 \%) \\
14(1.1 \%) \\
14(1.1 \%) \\
13(1.0 \%) \\
1(0.1 \%)\end{array}$ & $\begin{array}{l}147(10.6 \%) \\
45(3.3 \%) \\
27(2.0 \%) \\
63(4.6 \%) \\
18(1.3 \%) \\
6(0.4 \%)\end{array}$ \\
\hline $\begin{array}{l}\text { GastrointestinalTotal } \\
\text { Other } \\
\text { Crohn's disease } \\
\text { Ulcerative Colitis } \\
\text { Irritable Bowel Syndrome }\end{array}$ & $\begin{array}{l}40(3 \%) \\
11(0.8 \%) \\
10(0.8 \%) \\
10(0.8 \%) \\
9(0.7 \%)\end{array}$ & $\begin{array}{l}175(12.7 \%) \\
60(4.3 \%) \\
19(1.4 \%) \\
25(1.8 \%) \\
101(7.3 \%)\end{array}$ \\
\hline $\begin{array}{l}\text { OtherTotal } \\
\text { Auto-immune condition } \\
\text { Gynaecological condition } \\
\text { Other } \\
\text { Infectious disease } \\
\text { Skin condition }\end{array}$ & $\begin{array}{l}127(9.5 \%) \\
33(2.5 \%) \\
25(1.9 \%) \\
25(1.9 \%) \\
9(0.7 \%) \\
9(0.7 \%)\end{array}$ & $\begin{array}{l}165(11.9 \%) \\
64(4.6 \%) \\
31(2.2 \%) \\
35(2.5 \%) \\
12(0.9 \%) \\
43(3.1 \%)\end{array}$ \\
\hline
\end{tabular}




\section{INSERT Table 3}

\section{Patient Ratings of Effectiveness, Side-Effects and Other Adverse Consequences}

The symptoms most often managed with medical cannabis were pain $(48.0 \%, 666 / 1388)$, anxiety $(44.0 \%$, $611 / 1388)$, and sleep problems $(31.3 \%, 434 / 1388)$. The overwhelming majority of respondents reported symptom improvement following medical cannabis use (Fig. 2).

\section{INSERT Fig. 2}

Side effects were commonly reported (Table 4), although relatively few reported these to be severe and/or intolerable. 
Table 4

Side-Effect Profile of Medical Cannabis Use

\begin{tabular}{|lll|}
\hline & Severity & \\
\hline Side-Effect & Mild and Tolerable & Severe and/or Intolerable \\
\hline Dry Mouth $(\mathrm{n}=977)$ & $601(61.5 \%)$ & $23(2.4 \%)$ \\
\hline Increased appetite $(\mathrm{n}=976)$ & $578(59.2 \%)$ & $47(4.8 \%)$ \\
\hline Drowsy $(\mathrm{n}=976)$ & $534(54.7 \%)$ & $13(1.3 \%)$ \\
\hline Eye Irritation $(\mathrm{n}=974)$ & $294(30.2 \%)$ & $8(0.8 \%)$ \\
\hline Lack of Energy or Fatigue $(\mathrm{n}=973)$ & $287(29.5 \%)$ & $20(2.1 \%)$ \\
\hline Anxiety $(\mathrm{n}=974)$ & $228(23.4 \%)$ & $23(2.4 \%)$ \\
\hline Memory Impairment $(\mathrm{n}=973)$ & $227(23.3 \%)$ & $16(1.6 \%)$ \\
\hline Dehydration $(\mathrm{n}=975)$ & $220(22.6 \%)$ & $9(0.9 \%)$ \\
\hline Confusion $(\mathrm{n}=975)$ & $144(14.8 \%)$ & $9(0.9 \%)$ \\
\hline Respiratory complaints $(\mathrm{n}=973)$ & $141(14.5 \%)$ & $5(0.5 \%)$ \\
\hline Dizzy $(\mathrm{n}=974)$ & $137(14.1 \%)$ & $6(0.6 \%)$ \\
\hline Residual bad taste in mouth $(\mathrm{n}=973)$ & $135(13.9 \%)$ & $12(1.2 \%)$ \\
\hline Decreased Appetite $(\mathrm{n}=975)$ & $127(13.0 \%)$ & $8(0.8 \%)$ \\
\hline Paranoia $(\mathrm{n}=973)$ & $111(11.4 \%)$ & $9(0.9 \%)$ \\
\hline Racing heart or palpitations $(\mathrm{n}=972)$ & $106(10.9 \%)$ & $11(1.1 \%)$ \\
\hline Sweating $(\mathrm{n}=974)$ & $90(9.2 \%)$ & $10(1.0 \%)$ \\
\hline Depressed $(\mathrm{n}=974)$ & $87(8.9 \%)$ & $15(1.5 \%)$ \\
\hline Headaches $(\mathrm{n}=973)$ & $73(7.5 \%)$ & $11(1.1 \%)$ \\
\hline Sleep disturbance $(\mathrm{n}=973)$ & $72(7.4 \%)$ & $14(1.4 \%)$ \\
\hline Diarrhea $(\mathrm{n}=974)$ & $65(6.7 \%)$ & $7(0.7 \%)$ \\
\hline Constipation $(\mathrm{n}=974)$ & $52(5.3 \%)$ & $7(0.7 \%)$ \\
\hline Nasal Complaints $(\mathrm{n}=973)$ & $46(4.7 \%)$ & $8(0.8 \%)$ \\
\hline Gastro-Intestinal Irritation $(\mathrm{n}=973)$ & $44(4.5 \%)$ & $71(4.2 \%)$ \\
\hline Allergy $(\mathrm{n}=974)$ & $38(3.9 \%)$ & $9.5 \%)$ \\
\hline Panic Attacks $(\mathrm{n}=973)$ & & $9.7 \%)$ \\
\hline
\end{tabular}




\begin{tabular}{|lll|}
\hline \multicolumn{3}{|c|}{ Severity } \\
\hline Shaking/tremor $(\mathrm{n}=972)$ & $37(3.8 \%)$ & $4(0.4 \%)$ \\
\hline Nausea/vomiting $(\mathrm{n}=973)$ & $36(3.7 \%)$ & $6(0.6 \%)$ \\
\hline Delusion $(\mathrm{n}=974)$ & $24(2.5 \%)$ & $4(0.4 \%)$ \\
\hline Hallucinations $(\mathrm{n}=973)$ & $22(2.3 \%)$ & $3(0.3 \%)$ \\
\hline Cannabis hyperemesis $(\mathrm{n}=974)$ & $12(1.2 \%)$ & $8(0.8 \%)$ \\
\hline Other $(\mathrm{n}=970)$ & $3(0.3 \%)$ & $11(1.1 \%)$ \\
\hline
\end{tabular}

\section{INSERT Table 4}

Almost half the respondents $(47.6 \%, 448 / 942)$ indicated that the cost of Medical Cannabis placed a significant strain on their finances, $79.7 \%$ (751/942) worried about being arrested or other legal problems, and $37.5 \%$ (353/942) were worried about employment issues. 9.3\% of respondents (88/942) reported they had to undergo workplace drug testing.

\section{Accessing Medical Cannabis}

Respondents sourced their medical cannabis mainly from 'recreational dealers' (46.2\%, 482/1044), friends or family $(25.3 \%, 264 / 1044)$, by growing their own $(11.6 \%, 121 / 1044)$, from illicit medicinal cannabis suppliers $(7.2 \%, 75 / 1044)$, online suppliers $(5.1 \%, 53 / 1044)$ or 'other' sources $(4.7 \%, 49 / 1044)$. Only $2.7 \%$ of respondents $(25 / 931)$ indicated they had accessed licit medical cannabis prescribed by a doctor.

When asked why they had not accessed medical cannabis legally, $47.8 \%(433 / 906)$ of respondents indicated they did not know a medical practitioner willing to prescribe, 32.0\% (290/906) were not aware they could access medical cannabis legally, 21.2\% (192/906) indicated licit cannabis was too expensive, $18.4 \%$ (167/906) believed their medical practitioner was not interested or unwilling to prescribe cannabis, $12.7 \%(115 / 906)$ indicated they wanted their medical cannabis use to remain confidential from their healthcare providers, $9.5 \%(86 / 906)$ said they preferred illicit cannabis, and $11.6 \%(105 / 906)$ gave other reasons.

One quarter $(26.2 \%, 289 / 1101)$ reported not paying for their cannabis, but indicated they were willing to pay a weekly mean of AUD\$38.33 \pm 63.92 , (median AUD $\$ 25$, IQR: $\$ 10, \$ 50$ ) for prescribed products. Those respondents who did pay for cannabis estimated spending AUD\$82.30 \pm 101.00 per week (median $\$ 50$, IQR: $\$ 20, \$ 100$ ), and indicated that they were willing to pay AUD\$68.67 \pm 66.64 (median $\$ 50$, IQR: $\$ 25, \$ 100)$ for prescribed cannabis products.

\section{Accessing Information about Medical Cannabis}


When asked about their decision to try medical cannabis, most $(51.5 \%, 523 / 1015)$ indicated that they discovered the benefits on their own (using cannabis and noticed symptoms improved), $10.5 \%$ (107/1015) reported internet-based media (e.g. Facebook, Reddit), 9.9\% (100/1015) by a friend or family member, $6.5 \%$ (66/1015) by a medical cannabis advocacy group, $5.6 \%(57 / 1015)$ by a disease-specific consumer group, $5.0 \%(51 / 1015)$ by a healthcare provider, and the remainder $(10.9 \%, 111 / 1015)$ from other sources.

Although the initial interest in medical cannabis was generated by sources other than health professionals, most respondents $(63.2 \%, 641 / 1015)$ had discussed their medical cannabis use with a healthcare provider, including their GP $(83.6 \%, 536 / 641)$, medical specialist $(54.3 \%, 348 / 641)$, psychologist $(40.0 \%, 256 / 641)$, nurse $(17.5 \%, 112 / 641)$, alternative medicine provider $(17.2 \%, 110 / 641)$, and pharmacist $(12.9 \%, 83 / 641)$.

\section{Accessing Medically Prescribed Medicinal Cannabis Products}

The 25 respondents who had accessed prescribed medical cannabis products had been accessing it for an average of $4.8 \pm 3.8$ months (median 3 , IQR: 2,6 ), prescribed by a medical specialist $(64 \% ; 16)$ or GP $(36 \%, 9)$ for indications including fibromyalgia, multiple sclerosis, neuropathy, epilepsy, autism, Alzheimer's, mesothelioma, post-traumatic stress disorder, and back pain. Respondents estimated $18 \pm$ 22.5 weeks (median 12, IQR: 4, 25) between their first cannabis-specific consultation with their doctor and receiving their first dose of medical cannabis. Although the numbers were too small to draw any firm conclusions, feedback from the 25 respondents who had accessed medical cannabis legally indicated generally positive ratings of their experience of product consistency (17 [68\%] preferred licit supplies, 6 [24\%] preferred illicit supplies, 2 [8\%] no preference); ease of access (15 [60\%] preferred licit to 7 [28\%] illicit), cost (11 [44\%] preferred licit to 8 [32\%] illicit), effectiveness (11 [44\%] preferred licit to 6 [24\%] illicit), fewer side effects (13 [52\%] preferred licit to $5[20 \%]$ illicit), and legal status (20 [80\%] preferred licit to 2 [8\%] illicit).

\section{Attitudes to Regulation of Medical Cannabis}

Most respondents $(78.3 \%, 721 / 921)$ indicated that people should be able to buy and use medical cannabis without approval by a medical practitioner, $92 \%$ (850) that medical cannabis should be part of routine healthcare in Australia, 70.7\% (652) that the government should subsidise the cost of medical cannabis and $91.1 \%$ (839) that medical cannabis should meet safety standards (e.g. known strength, composition and contaminant-free). Most thought that the Australian regulatory framework for accessing medical cannabis did not work well $(91.0 \%, 838 / 921)$, that the cost of licit medical cannabis was prohibitively expensive $(62.6 \%, 577 / 921)$, and that the current model was difficult for patients to negotiate $(87.3 \%, 804 / 921)$.

\section{Discussion}


This survey provides a number of insights into medical cannabis use within the Australian community and updates our understanding of how consumer perspectives since the introduction of legal access pathways in November 2016. In many respects, little has changed in the two years since cannabis was legalised for medicinal purposes in Australia: users are still largely accessing illicit cannabis, selfmedicating a similar range of health conditions (chronic pain, mental health and sleep problems), with similar perceived levels of effectiveness, side effects, and social and issues. The current survey recruited a slightly older (43.4 \pm 13.9 compared to $37.9 \pm 13.4$ years) and more educated cohort than CAMS-16. Respondents reported using cannabis on fewer days in the past 4 weeks ( $15.8 \pm 11.2$ compared to $19.9 \pm$ 10 days in CAMS-16), although they spent similar amounts for their medical cannabis, averaging just over AUS\$80 per week (compared with under AUD\$70 per week in CAMS-16). These differences in participant characteristics may reflect changes in recruitment sources strategies (more Twitter in CAMS18 than Facebook), and/or may reflect the changing profile of Australian users.

There is little in the current survey results to suggest that two years of legal medical cannabis access in Australia has transformed the 'landscape' of medical cannabis. The vast majority of respondents had not used the legal avenues available for prescription, with many respondents perceiving difficulties in finding medical practitioners willing to prescribe, and/or citing cost and stigma as barriers. Whilst few study respondents $(n=25)$ had accessed legal medical cannabis, those that had generally had more favourable perceptions regarding the legal form of the drug than those who had only ever used illicit forms. Interestingly the majority of the respondents who used licit medical cannabis preferred it to illicit for its cost ease of access, however cost and ease of access were both endorsed as important barriers to accessing licit medical cannabis by respondents who had never obtained medical cannabis legally.

The predominant continuing use of illicit sources reflects the relatively limited uptake of TGA SAS-B approvals prior to the survey ${ }^{11}$. In the 6 months prior to September 2018, when the CAMS-18 survey opened, fewer than 1200 patients had been granted SAS-B approvals although approximately 3000 approvals were granted during the study recruitment period (September 2018 to March 2019). However, in the 6-month period following the close of the CAMS-18 survey in March 2019 over 13,000 approvals have been granted ${ }^{6}$. Future surveys will attempt to explore this expansion in regulatory approvals and the impact upon medical cannabis consumers.

Our findings identify ongoing concerns regarding illicit supplies. There was scant knowledge of the composition of the products being used with regard to cannabinoid content (e.g. THC, CBD). This represents a fundamental issue given that the two cannabinoids have quite distinct clinical indications and therapeutic effects. Even for those who thought they knew the composition of their cannabis products, it is worth noting that there is essentially no capacity for consumers to determine the strength or composition of illicit cannabis products in Australia, with no ability for laboratory testing of illicit cannabis products. In a previous study by our group, there was considerable discrepancy between perceived and actual cannabinoid profiles of illicit cannabis supplies used for children with epilepsy ${ }^{12}$. Similarly, almost two thirds of respondents were worried about potential contaminants. These are not ideal conditions for any therapeutic intervention in a modern healthcare system. 
One positive trend in the current survey relative to CAMS-16 is a move away from smoking (joints, bongs) to non-smoked cannabis-based products - with greater numbers in the current survey using vaporisers

and oral liquid extracts, a trend also emerging in other countries ${ }^{15-18}$. Whilst any non-smoked route is to be preferred, the apparent proliferation of artisanal medical cannabis producers reiterates concerns regarding quality control and standards of production in illicit operations, as highlighted in recent health concerns regarding vaporisation of illicit cannabis-based products ${ }^{19,20}$.

Demand for medical cannabis products does not seem to be abating. The experience of consumers surveyed here suggests minimal uptake of licit and prescribed products during the first two years, although there are indications that this is changing. The marked increase in SAS approvals since the close of this survey signals improved access to medical providers willing to engage in this area of medicine - coinciding with the emergence of a number of private clinics specialising in medicinal cannabis, which appears to have markedly increased access to medicinal cannabis products. Our survey indicates that medical practitioners (GPs and specialists) continue to be seen as valued sources of information regarding medical cannabis, although Australian GPs themselves feel relatively 'undereducated' regarding medical cannabis ${ }^{19}$. Finally, whilst most respondents in our survey continued to express disappointment with the legal models of medical cannabis availability, those who had actually pursued the licit avenue reported quite positive experiences.

The study design has inherent limitations, as described previously ${ }^{10}$. The reliance on self-report data is potentially associated with inaccurate information, such as incorrect diagnostic conditions, recall difficulties, or misinterpretation of effectiveness or adverse events. Furthermore, there is always likely to be a selection bias in any such survey towards recruiting people with favourable experiences of medical cannabis and cannabis legalisation generally. Whilst we were able to reduce the amount of missing data compared to the CAMS-16 survey, we acknowledge that valid responses to all questions were only available for $65 \%$ of respondents.

\section{Conclusions}

Our survey reflects the experiences of consumers during the first two years after major regulatory changes permitting medical cannabis access to patients. The early experiences of the small numbers of patients who had accessed legally prescribed products appear positive, although there remain many negative perceptions of access pathways amongst most consumers surveyed. It remains to be seen how many of the individuals using illicit cannabis products for medical reasons legally will transfer to legally prescribed products over time. Until some form of medicinal-grade cannabinoid product is added to the list of medications subsidised by the Australian government via the Pharmaceutical Benefits Scheme, cost seems likely to remain a barrier to widespread use of licit medical cannabis. Another potential concern is the many SAS-B approvals that have being granted for conditions for which there is little evidence and no clinical guidance (e.g. over 800 approvals have been granted to treat anxiety ${ }^{8}$ ). Given that many in the community are already using illicitly-obtained cannabis to treat their anxiety, depression, 
and insomnia there is an urgent need for more clinical trials to investigate the effectiveness of cannabis products for these conditions.

\section{Declarations}

Ethics Approval and Consent to Participate: This study was approved by the Sydney University Human Research ethics Committee (2018/544). In order to begin the survey participants were asked to read a linked Participant Information Statement and to tick a check box giving consent for their data to be used in the study

Consent for Publication: Not applicable

Availability of Data and Materials: The datasets used and/or analysed during the current study are available from the corresponding author on request.

Competing Interests: Dr Lintzeris reports grants from the Australian National Health and Medical Research Council (NHMRC) during the conduct of the study; grants from Camurus, personal fees from Indivior, and personal fees from Mundipharma unrelated to the submitted work; and, being the Clinical Director of the Lambert Initiative in Cannabinoid Therapeutics at University of Sydney from 2015-17, was involved in a number of other studies of medical cannabis unrelated to the submitted work. Dr McGregor reports grants from NHMRC and grants from Lambert Initiative for Cannabinoid Therapeutics during the conduct of the study for projects unrelated to the submitted work; Dr McGregor has a patents to W02018107216A1, W02017004674A1, and W02011038451A1 issued and licensed, and patents to AU2017904438, AU2017904072, and AU2018901971 pending. No other authors report conflicts of interest.

Funding. This research received no specific grant from any funding agency in the public, commercial, or not-for-profit sectors.

Authors' contributions: All authors contributed to design of the study questionnaire. N Lintzeris and L Mills had full access to all the data in the study and take responsibility for the integrity of the data and the accuracy of the data analysis. $N$ Lintzeris and L Mills wrote the manuscript and created all Tables and Figures. All authors provided comments and edited the finished manuscript.

Acknowledgements. We would like to acknowledge the important contribution of Associate Professor David Allsop to the creation of the original CAMS-16 questionnaire, upon which the CAMS-18 questionnaire was based. It seems not even death can curb Dave's research output.

\section{References}


1. National Academies of Sciences Engineering Medicine. The health effects of cannabis and cannabinoids : the current state of evidence and recommendations for research. Washington, DC: The National Academies of Science, Engineering, and Medicine;2017.

2. Hall W. European Union: Medical use of cannabis and cannabinoids: questions and answers for policymaking. EMCDDA;2018;Lisbon.

3. Advisory Committee on Medicine Scheduling. Final decisions and reasons for decisions by a delegate of the Secretary to the Department of Health [report]. Australian Government Department of Health, Therapeutic Goods Administration; 31 Aug, 2016. Available at: https://www.tga.gov.au/sites/default/files/scheduling-delegates-final-decisions-cannabis-andtetrahydrocannabinols-march-2016_0.pdf. Accessed 10th of October, 2019.

4. Australian Government. Narcotic Drugs Amendment Act, No.12, 2016. Federal Register of Legislation; 2 Mar 2016. Available at: https://www.legislation.gov.au/Details/C2016A00012. Accessed 10th of October, 2019.

5. McEwen J. A history of therapeutic goods regulation in Australia. Canberra: Commonwealth of Australia, 2007. Available at: https://www.tga.gov.au/sites/default/files/history-tgregulation.pdf. Accessed 10th of October, 2019.

6. Therapeutic Goods Administration. Access to Medicinal Cannabis Products. 2019; https://www.tga.gov.au/access-medicinal-cannabis-products-1. Accessed 10th of October, 2019.

7. Freshleaf Analytics. Australian Medicinal Cannabis Pricing Analysis, Q3 2018. Cannabis Access Clinics; 2018.

8. Therapeutic Goods Administration. Freedom of Information Request 1311: SAS-B Medicinal Cannabis Approvals. Canberra: Australian Government Department of Health;2019.

9. Benson M, Cohen R. Does Medicinal Cannabis actually help Australian Patients? The answer might be hiding in plain sight. Health Europa Quarterly. 2019(10):188-191.

10. Lintzeris N, Driels J, Elias N, Arnold JC, McGregor IS, Allsop DJ. Medicinal cannabis in Australia, 2016: the Cannabis as Medicine Survey (CAMS-16). Med J A. 2018; 209(5):211-216.

11. Hurst $\mathrm{H}$, Bolton J. Assessing the clinical significance of change scores recorded on subjective outcome measures. J Manipulative Physiol Ther. 2004;27(1):26-35.

12. Harris PA, Taylor R, Thielke R, Payne J, Gonzalez N, Conde JG. Research electronic data capture (REDCap)-A metadata-driven methodology and workflow process for providing translational research informatics support. J Biomed Inform. 2009;42(2):377-381.

13. R: A language and environment for statistical computing [computer program]. R Foundation for Statistical Computing; 2016.

14. Wickham H. Tidyverse: Easily install and load 'tidyverse' packages. $R$ package version. 2017;1(1).

15. Barrus DG, Capogrossi KL, Cates SC, et al. Tasty THC: Promises and Challenges of Cannabis Edibles. Methods Rep RTI Press. 2016;2016:10.3768/rtipress.2016.op.0035.1611. 
16. Pacula RL, Jacobson M, Maksabedian EJ. In the weeds: a baseline view of cannabis use among legalizing states and their neighbours. Addiction. 2016;111(6):973-980.

17. Cranford JA, Bohnert KM, Perron BE, Bourque C, Ilgen M. Prevalence and correlates of "Vaping" as a route of cannabis administration in medical cannabis patients. Drug Alcohol Depend. 2016;169:4147.

18. Russell C, Rueda S, Room R, Tyndall M, Fischer B. Routes of administration for cannabis use - basic prevalence and related health outcomes: A scoping review and synthesis. Int $\mathrm{J}$ Drug Policy. 2018;52:87-96.

19. Layden JE, Ghinai I, Pray I, et al. Pulmonary IIIness Related to E-Cigarette Use in Illinois and Wisconsin - Preliminary Report. N Engl J Med. 2019.

20. Schier JG, Meiman JG, Layden J, et al. Severe pulmonary disease associated with electroniccigarette-product use-interim guidance. Centre for Disease Control, Morbidity and Mortality Weekly Report. 2019;68(36):787.

\section{Figures}




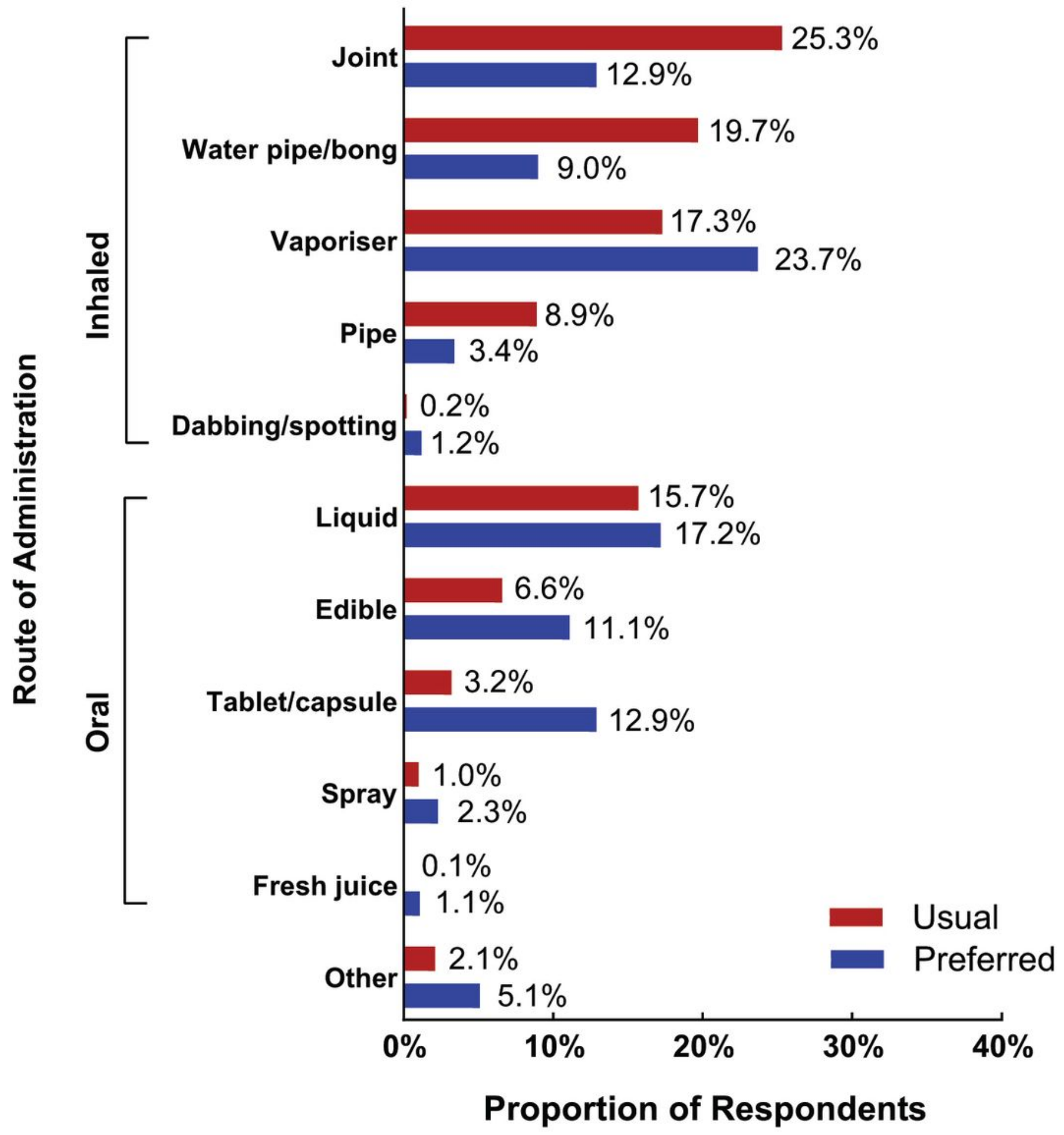

Figure 1

Most respondents consumed their cannabis via an inhaled $(71.4 \% ; 788 / 1104)$ or oral $(26.5 \%, 293 / 1104)$ route, although there was a much stronger preference for oral or vaporised routes of administration than smoked routes 


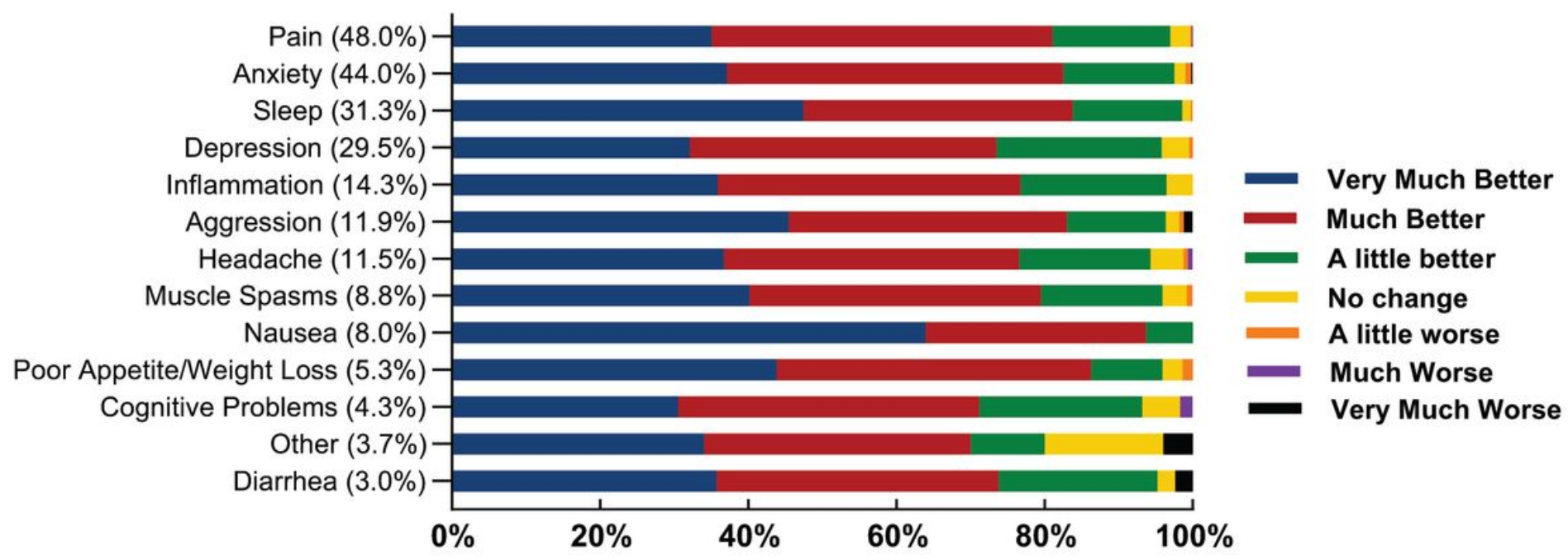

Figure 2

The symptoms most often managed with medical cannabis were pain $(48.0 \%, 666 / 1388)$, anxiety $(44.0 \%$, $611 / 1388)$, and sleep problems $(31.3 \%, 434 / 1388)$. The overwhelming majority of respondents reported symptom improvement following medical cannabis use 